\title{
In vitro response to influenza immunisation by peripheral blood mononuclear cells from patients with systemic lupus erythematosus and other autoimmune diseases
}

\author{
L TURNER-STOKES, ${ }^{1}$ G CAMBRIDGE, ${ }^{1}$ T CORCORAN, ${ }^{2}$ J S OXFORD, ${ }^{2}$ \\ AND M L SNAITH
}

From the 'Bloomsbury Rheumatology Unit and Department of Rheumatology Research, University College and The Middlesex Hospital School of Medicine, London; and the ${ }^{2}$ National Institute for Biological $خ$ Standards and Controls, South Mimms, Herts SUMMARY Reduced in vitro anti-influenza antibody response by peripheral blood mononuclear
cells (PBMs) after vaccination was confirmed in a group of 28 patients with systemic lupus
erythematosus (SLE), and also in 16 patients with some other autoimmune syndromes. This
group of patients with SLE had higher serum anti-DNA binding, but there was no evidence of
increased autoantibody production after vaccination, nor any clinical or laboratory evidence of
flares in disease activity that are sometimes seen to follow intercurrent infection. Although a
reduced in vitro antibody response may, to some extent, reflect redistribution of antibody
producing cells, there appears to be more generalised impairment of the immune response in
these patients, which cannot be accounted for by steroid/immunosuppressive therapy.

B cell hyperactivity and autoantibody production characterise systemic lupus erythematosus (SLE). ${ }^{1}$ It is our clinical impression that flares of disease activity may be related to intercurrent infection. Although not well researched, this observation is not new. ${ }^{2}$ One possible mechanism could be the production of potentially damaging autoantibodies in response to challenge with exogenous antigen, either concurrently with, or at the expense of the specific antibody response. It is therefore pertinent to ask $(a)$ Is the immune response to challenge with exogenous antigen impaired in SLE? $(b)$ Does such a challenge stimulate autoantibody production? (c) If so, is this confined to SLE or does it occur in other autoimmune diseases?

We took advantage of routine influenza immunisation to address these questions. Previous small studies of the immune response to influenza immunisation in SLE suggest abnormal in vitro antibody production by peripheral blood mononuclear cells (PBMs) from patients with SLE, despite a 'normal' serum response (greater than

Accepted for publication 14 January 1988.

Correspondence to Dr L Turner-Stokes. Bloomsbury Rheumatology Unit, 3rd Floor, Arthur Stanley House, London WIP 9PG. fourfold rise in titre). ${ }^{3-5}$ Active disease or immunosuppressive therapy could account for these findings, and a larger study including other autoimmune disorders was clearly indicated.

\section{Patients, materials, and methods}

PATIENTS

The immune response to influenza vaccination was 음 assessed in 28 patients with SLE, all of whom fulfilled at least four of the 1982 revised criteria for the classification of SLE. ${ }^{6}$ Sixteen patients with $N$ other autoimmune diseases were also studied: 10 with classical rheumatoid arthritis (RA), four ${ }_{N}$ with mixed connective tissue disease (MCTD), and $\omega$ two with RA/SLE crossover syndromes. The control groups comprised 35 normal individuals selected 0 from laboratory, medical, and secretarial staff and $\bar{\Phi}$ six patients receiving steroids for non-autoimmune $\stackrel{?}{+}$ conditions, mainly chronic air-flow limitation. $\frac{T}{T}$ Informed consent was obtained from all subjects, $\stackrel{\circ}{\mathbb{D}}$ and the study was approved by the hospital ethical committee.

MATERIALS AND METHODS

Merieux influenza vaccine (Servier) was given by응 
subcutaneous innoculation into the non-dominant arm. The study period spanned two seasons. Vaccine for the first season (1985-6) contained $\beta$-propiolactone inactivated A/Philippines/82 (H3N2), A/ Chile/83 (H1N1), and B/USSR/83; and for the second season (1986-7), A/Mississippi/85 (H3N2), A/ Chile/83 (H1N1), and B/Ann Arbor/86.

\section{Lymphocyte culture}

After vaccination serum and PBMs were collected at seven day intervals up to 28 days. In vitro production of anti-influenza antibody was determined using the method described by Callard. ${ }^{7}$ Briefly, PBMs were separated by density gradient centrifugation over Ficoll-Hypaque (Pharmacia), washed in Hanks's balanced salt solution, and resuspended in RPMI 1640 containing 25 mM HEPES (N-2-hydroxyethylpiperazine- $N^{\prime}$-2-ethanesulphonic acid), $2 \mathrm{~g} / 1$ bicarbonate (Gibco) and $10 \%$ horse serum (Sera Labs) at a concentration of $2 \times 10^{6}$ cells $/ \mathrm{ml}$. One millilitre volumes were cultured in sterile capped $12 \times 75 \mathrm{~mm}$ tubes (Falcon 2054), either alone or in the presence of optimal concentrations of sucrose density gradient purified influenza virus $A / \times 79$ (H3N2), A/×87 (H3N2), A/ ×83 (H1N1), B/USSR, B/Ann Arbor, or pokeweed mitogen. After six days of culture in a $5 \% \mathrm{CO}_{2}$ atmosphere at $37^{\circ} \mathrm{C}$ the cells were washed and resuspended in RPMI 1640 containing $5 \%$ fetal calf serum for a further 24 hour culture period before supernatants were collected and frozen for batch analysis.

\section{Anti-influenza antibody assay}

Anti-influenza antibody in culture supernatants was determined by solid phase enzyme immunoassay. ${ }^{8}$ Briefly, influenza viruses (see above) were adsorbed onto microtitre plates (Nunc Immuno 1) and nonspecific binding sites blocked with $1 \%$ bovine serum albumin. Culture supernatants were then added to virus coated wells, and after incubation and washing goat antihuman polyvalent immunoglobulin conjugated to alkaline phosphatase (Sigma) was added. Bound conjugate was detected using nitrophenol phosphate substrate (Sigma), and the optical density

Table 1 Anti-influenza antibody response, clinical parameters, and treatment in 28 patients with SLE

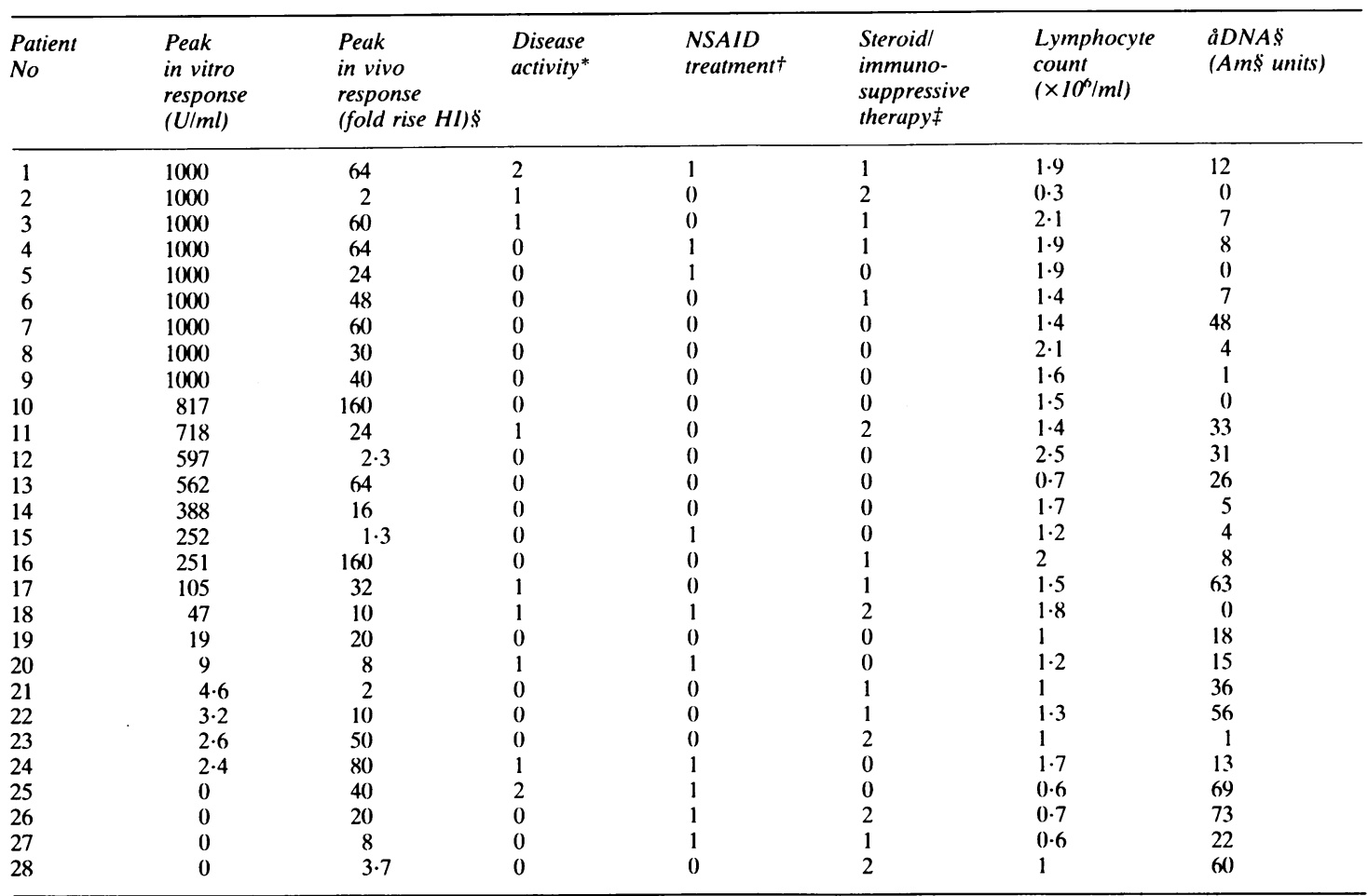

${ }^{*}$ Activity: $0=$ inactive; $1=$ moderately active; $2=$ active.

+ NSAID = non-steroidal anti-inflammatory drug: $0=$ not receiving NSAIDs; $1=$ recciving NSAIDs.

Immunosuppressive therapy: $0=$ none; $1=$ steroids only; $2=$ steroids and azathioprinc/cyclophosphamide.

$\S \mathrm{HI}=$ hacmagglutination inhibition; åDNA=anti-DNA antibodics; $\mathrm{Am}=$ Amersham. 
read at $405 \mathrm{~nm}$ on a Dynatech MR 580 automatic colorimeter. The results of duplicate cultures were expressed as units $/ \mathrm{ml}$ of specific antibody calculated from a standard curve of logit transformed optical density versus $\log _{n}$ (concentration) of specific antibody prepared for each plate. Values below 2 units $/ \mathrm{ml}$ were considered insignificant.

Serum anti-influenza antibody levels were determined by standard microtitre methods."

Anti-DNA antibody assay

Anti-DNA binding in culture supernatants was determined by a similar enzyme immunoassay. ${ }^{10}$

Serum anti-DNA binding was measured with the Amersham kit.

\section{Statistics}

Group comparison were made with the $\chi^{2}$ test. The data, which were not normally distributed, were analysed by non-parametric statistical tests.

\section{Results}

The mean ages of the patient and control groups were 42.3 and 41.2 years respectively, with ranges of 19-72 and 19-64 years. No patient developed a flare in disease activity after vaccination.

In vitro and serum antibody responses to each of the viruses in the vaccine were measured before and at timed intervals after vaccination. Antibodies to these strains were not detected in unstimulated cultures before immunisation. There was considerable individual variation in both in vitro and in vivo responses to immunisation, but a number of subjects made consistently low in vitro specific antibody responses $(<10$ units $/ \mathrm{ml})$ to all of the influenza antigens. These patients are referred to as 'nonresponders'.

Reduced in vitro specific antibody responses were found in $9 / 28(32 \%)$ of patients with SLE, $3 / 4$ with MCTD, and both patients with RA/SLE crossover syndromes, as opposed to $3 / 35(9 \%)$ normal controls $\left(\chi^{2} \mathrm{p}<0.001\right)$. Interestingly only $2 / 10(20 \%)$ patients with classical RA had an impaired response. In those patients who did have in vitro responses, however, these were not quantitatively different from those of the normal control population, although there was considerable variation between individuals.

When a population of in vitro non-responders was identified among the patients with SLE, associations with a wide range of clinical parameters of the disease were sought. Table 1 shows the distribution of some of these (disease activity, serum anti-DNA binding, lymphopenia, and immunosuppressive therapy) among in vitro responders and nonresponders.
Table 2 shows the statistical analysis of these $\frac{\mathrm{O}}{\omega}$. associations. An impaired in vitro anti-influenza antibody response was significantly associated with a $\stackrel{\stackrel{9}{\rightarrow}}{\rightarrow}$ lymphocyte count of less than $1 \cdot 3 \times 10^{6} / \mathrm{ml}(\mathrm{p}<0 \cdot(001)$ 을 (Fig. 1) and higher serum anti-DNA antibodies $(p<0.02)$ (Fig. 2). There was no significant associa- $\frac{\omega^{n}}{2}$ tion with disease activity or immunosuppressive $\stackrel{\mathbb{\Omega}}{\varrho}$ therapy. Eighteen patients and six controls received an influenza vaccination in both seasons of the study. The response to second time vaccination was significantly lower, both in vivo and in vitro. Although most of the in vitro non-responders had a greater than fourfold rise in serum antibody titre after vaccination, the peak serum response was significantly lower than in in vitro responders. matched for age, treatment, and previous vaccina- $\dot{ }$ tion $(\mathrm{p}<0 \cdot 003)$.

Table 2 Associations with an impaired anti-influenza antibody response in vitro in patients with $S L E$

\begin{tabular}{|c|c|c|}
\hline Association & Test & $\begin{array}{l}\text { Significance } \\
\text { (p value) }\end{array}$ \\
\hline $\begin{array}{l}\text { Lymphopenia } \\
\qquad<1 \cdot 3 \times 10^{6} / \mathrm{ml}\end{array}$ & Mann-Whitney & $0 \cdot 001$ \\
\hline $\begin{array}{l}\text { Higher serum } \\
\text { DNA binding }\end{array}$ & $\begin{array}{l}\text { Kruskal-Wallis } \\
\text { one way } \\
\text { ANOVA* }\end{array}$ & 0.0137 \\
\hline Discase activity & $\chi^{2}$ & NS \\
\hline $\begin{array}{l}\text { Steroids/immuno- } \\
\text { suppressive therapy } \\
\text { Previous vaccination }\end{array}$ & $\begin{array}{l}\chi^{2} \\
\text { Kruskal-Wallis } \\
\text { one way } \\
\text { ANOVA }\end{array}$ & 0.0320 \\
\hline $\begin{array}{l}\text { Lower serum specific } \\
\text { antibody response }\end{array}$ & $\begin{array}{l}\text { Wilcoxon signed } \\
\text { rank }\end{array}$ & $0 \cdot 003$ \\
\hline
\end{tabular}

${ }^{*}$ ANOVA $=$ analysis of variance.

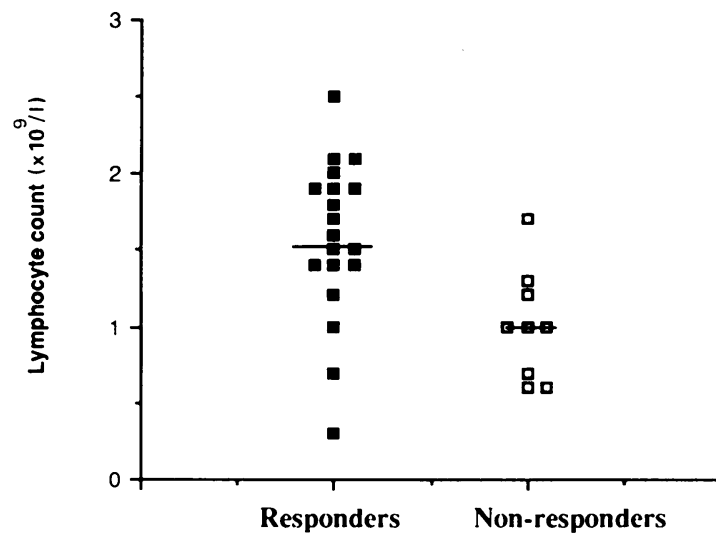

Fig. 1 Patients with SLE with impaired in vitro influenza responses have lower peripheral blood lymphocyte counts. 


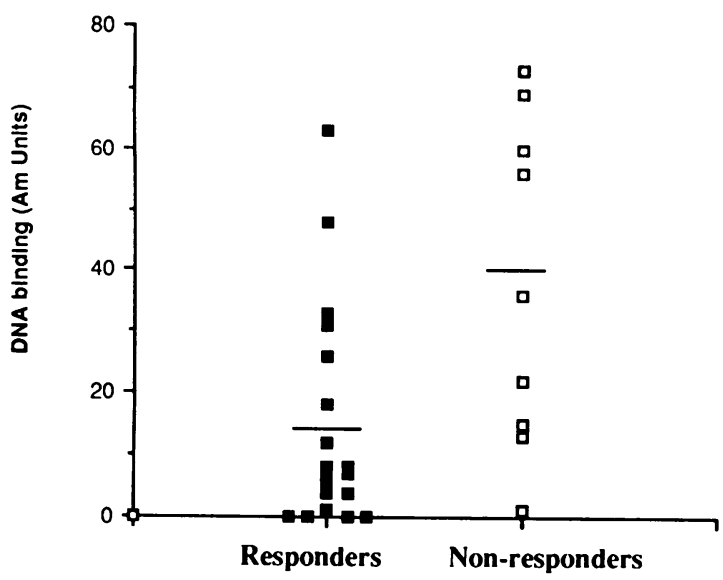

Fig. 2 Patients with SLE with impaired in vitro influenza responses have higher serum anti-DNA binding.

\section{Discussion}

Spontaneous antibody production to a variety of self and environmental antigens is seen in SLE. "It has been suggested that such preactivation explains the failure of pokeweed mitogen to stimulate further immunoglobulin production in PBMs from these patients. ${ }^{11}$ Spontaneous production of antibody to A/Hong Kong/ $\times 31$ (the virus responsible for the 1968 pandemic) has recently been demonstrated in patients with SLE by Dar et al. ${ }^{12}$ Such preactivation could account for the failure of the earlier studies to demonstrate in vitro responses to influenza immunisation, as they all measured the antibody response to this antigen. In this study the use of a related but antigenically distinct virus, to which the patients showed no response before immunisation, may explain the fact that most patients are shown to have in vitro responses which are not quantitatively different from those of age and sex matched normal controls. As in the earlier studies, however, we did identify a group of patients with SLE with impaired anti-influenza antibody production by PBMs in vitro after immunisation. This was also seen in other autoimmune conditions, such as MCTD and RA/SLE crossover syndromes, but to a lesser extent in classical RA.

Depression of the in vitro response could have been the result of steroid and other immunosuppressive therapy needed to control active disease, or overproduction of autoantibodies at the expense of the anti-influenza response. Our results show, however, that impaired in vitro response was not associated either with immunosuppressive therapy or with active disease. The in vitro non-responders had higher serum anti-DNA levels than responders, but no rise in titre was seen after vaccination, and anti-double-stranded DNA antibodies were not detected in any of the culture supernatants on stimulation with influenza virus.

An alternative explanation for failure of in vitro response in certain autoimmune patients could be sequestration of influenza activated B cells in the lymphoid tissue, as demonstrated by Souhami et al for the response to varicella in patients with Hodgkin's disease. ${ }^{13}$ We have demonstrated specific antibody production by lymph node lymphocytes in in vitro non-responders (unpublished data), suggesting that such sequestration may indeed occur. Although there was no clear correlation between in vitro and in vivo antibody responses, careful matching of patients for age, disease, therapy, and previous vaccination showed significantly lower serum responses in the in vitro non-responders. So it would appear that there is also some generalised impairment of the immune response to influenza antigen in these patients.

\section{References}

1 Fauci A S. Steinberg A D, Haynes B F. Whalen G. Immunoregulatory aberrations in systemic lupus erythematosus. J Imınunol 1978: 121: 1473-9.

2 Ropes M W. Systemic lupus erythematosus. Cambridge, Mass: Harvard University Press, 1976.

3 Mitchell D M. Fitzharris P. Knight R A. Schild G C. Snaith M L. Kinetics of specific antibody production by cultured lymphocytes from patients with systemic lupus erythematosus following influenza immunization. Clin Exp Immunol 1982; 49: 290-6.

4 Pelton B K. Denman M. Defective B cell function in systemic lupus erythematosus. Clin Exp Immunol 1982; 48: 513-8.

5 Hari Kumar M K. Knight R A. Snaith M L. Specific allogeneic help by $T$ lymphocytes from patients with systemic lupus erythematosus. Clin Exp Immunol 1984: 58: 21-8.

6 Tan E M. Cohen A S. Fries J F, et al. The 1982 revised criteria for the classification of systemic lupus erythematosus. Arthritis Rheum 1982; 25: 1271-7.

7 Callard R E. Specific in vitro antibody response to influenza virus by human blood lymphocytes. Nature 1979: 282: 734-6.

8 Callard R E. Smith C M. Histocompatibility requirements for $T$ cell help in specific in vivo antibody responses to influenza virus by human blood lymphocytes. Eur J Immunol 1981; 11: 206-12.

9 Palmer D F, Dowdle W R, Coleman M T, Schild G C. Advanced laboratory techniques for influenza diagnosis. USDHEW, centre for disease control. Immunology series 1975; 6: $25-62$.

10 Isenberg D A, Maddison P, Swana G, et al. Profile of autoantibodies in the serum of patients with tuberculosis, klebsiella and other Gram-negative infections. Clin Exp Immunol 1987; 67: 516-23.

11 Nies K M, Louie J S. Impaired immunoglobulin synthesis by peripheral blood lymphocytes in systemic lupus erythematosus. Arthritis Rheum 1978; 21: 51-7.

12 Dar O. Salamn M R, Scifert M H. Isenberg D A. The role of polyclonal activation in the development of SLE. Br J Rheumatol 1987; 26 (suppl): 74.

13 Souhami R L, Babbage J, Sigfussen A. Defective in vitro antibody production to varicella zoster and other virus antigens in patients with Hodgkin's disease. Clin Exp Immunol 1983; 53: 297-307. 